\title{
The Influence of Nationality and Gender on Ethical Sensitivity: An Application of the Issue-Contingent Model
}

\author{
Can Simga-Mugan \\ Bonita A. Daly \\ Dilek Onkal \\ Lerzan Kavut
}

\begin{abstract}
When a member of an organization has to make a decision or act in a way that may benefit some stakeholders at the expense of others, ethical dilemmas may arise. This paper examines ethical sensitivity regarding the duties to clients and owners (principals), employees (agents), and responsibilities to society (third parties). Within this framework, ethical perceptions of male and female managers are compared between the U.S. and
\end{abstract}

Can Simga-Mugan is a Professor of Accountancy at Department of Business Administration of Middle East Technical University, Ankara, Turkey. She received her Ph.D. in accountancy from University of Illinois-Urbana-Champaign. Her current research interests are ethics, international financial reporting issues, manipulation in the stock market and effect of news on the stock market.

Bonita A. Daly, Ph.D., is an Assistant Professor of Accounting in the School of Business, University of Southern Maine in Portland, Maine. She teaches auditing and financial accounting to both undergraduate and graduate students. Dr. Daly also teaches business ethics in continuing education programs for practicing accountants. Her research on the accounting profession has appeared in Critical Prespectives on Accounting, Accounting, Organizations, and Society, and the St. John's Law Review, among others.

Dilek Onkal is a Professor of Decision Sciences and is currently the Acting Dean of the Faculty of Business Administration at Bilkent University, Turkey. She received a Ph.D. in Decision Sciences from the University of Minnesota, and is doing research on ethics judgements, risk perception, risk communication, and judgmental forecasting.

Lerzan Kavut is an Associate Professor at Faculty of Business Administration of Istanbul University. She has received her B.A. and Ph.D. from Istanbul University. Her current research interest is in the area of behavioral auditing.
Turkey - two countries that differ on power distance as well as the individualism/collectivism dimensions. Our results show that ethical sensitivity varies depending upon whether the interests of principals, agents, or third parties are affected by a given ethical dilemma. We also find that, contingent upon the principal-agent-society relationships, the nationality and gender of the decision-maker influences ethical sensitivity.

KEY WORDS: context, cross-cultural, ethics, ethical sensitivity, gender, Hofstede, issue-contingent model, Kohlberg, nationality, roles

\section{Introduction}

One of the significant impacts of globalization is that business organizations operate across cultures. Depending on how management responds to different values and beliefs, cultural diversity may substantially affect an organization's performance (Blanchard, 1998; Stodder, 1998). Cultural values are generally defined as the values and beliefs learned in day-to-day living within a particular society, starting in early childhood. These values and beliefs are usually considered relatively resistant to change (Beck and Moore, 1985). Although there are some universal values such as honesty, integrity, fairness, and not harming others, the concept of what is "right" and "wrong" varies across national boundaries and even within countries consisting of different sub-cultures (Schwartz, 2002). 
As companies become truly global, resistance to the transfer of parent company ethical values to the host country may arise. To achieve their objectives, managers of multinational companies acknowledge that they must often adapt their ways of doing business to the "host culture" (Asgary and Mitschow, 2002; Joyner and Payne, 2002). In an extensive study of culture and management practices in 18 countries, Newman and Nollen (1996) found that the financial performance of regional units was higher when management practices were compatible with local beliefs and values. The results of a study of 210 managers from four different countries, one of which was the U.S., suggest that individuals make ethical judgments based upon complex interactions among multiple variables (Robertson et al., 2002). These variables are the cultural background of the decisionmaker, the situation (threat to one's economic well being versus survival of the organization), and the specific issue that poses an ethical dilemma.

A different stream of research focuses on the distinction between the "ethics of justice" and the "ethics of care" propositions. According to this framework, ethics of justice emphasizes equality, principles, and results. In contrast, ethics of care gives more weight to social virtues and character traits, such as nurturing and caring for others (Betz et al., 1989; Dawson, 1995; Derry, 1989; Dienhart, 1995; Douglas and Schwartz, 1999; French and Weis, 2000; Gilligan, 1982; Lyons, 1988; MacIntyre, 1984; Reiter, 1996; Tronto, 1993). The common findings of these studies are that women display higher ethical standards than do men and that moral reasoning processes differ between the two genders. Women tend to use "ethics of care" while men utilize "ethics of justice."

Researchers who emphasize the importance of one's culture suggest that when facing moral dilemmas, people from Western and masculine cultures utilize ethics of justice. In contrast, people who are from Eastern and feminine cultures draw upon ethics of care (Hofstede, 1980). Moreover, individualistic cultures are argued to value independence, choice, and self-interest more than they do the society's interests. In comparison, collectivistic cultures are thought to place society's welfare before their own interests, anticipating that their community will protect their interests (Hofstede, 1980). Fijneman et al. (1996) empirically tested this theory across cultures and determined that emotional and psychological closeness prove to be very helpful in explaining individuals' ethical behavior, regardless of the culture or gender. Supporting Fijneman et al. (1996), the issue-contingent model suggests that an individual's ethical sensitivity and behavior may be primarily affected by the moral intensity of the issue under consideration (Jones, 1991).

Figure 1 depicts our view that the factors influencing an individual's ethical sensitivity interact. National (cultural) values or characteristics and gender influence and shape an individual's beliefs and values. These interact with the context of an ethical dilemma, such as role-related responsibilities

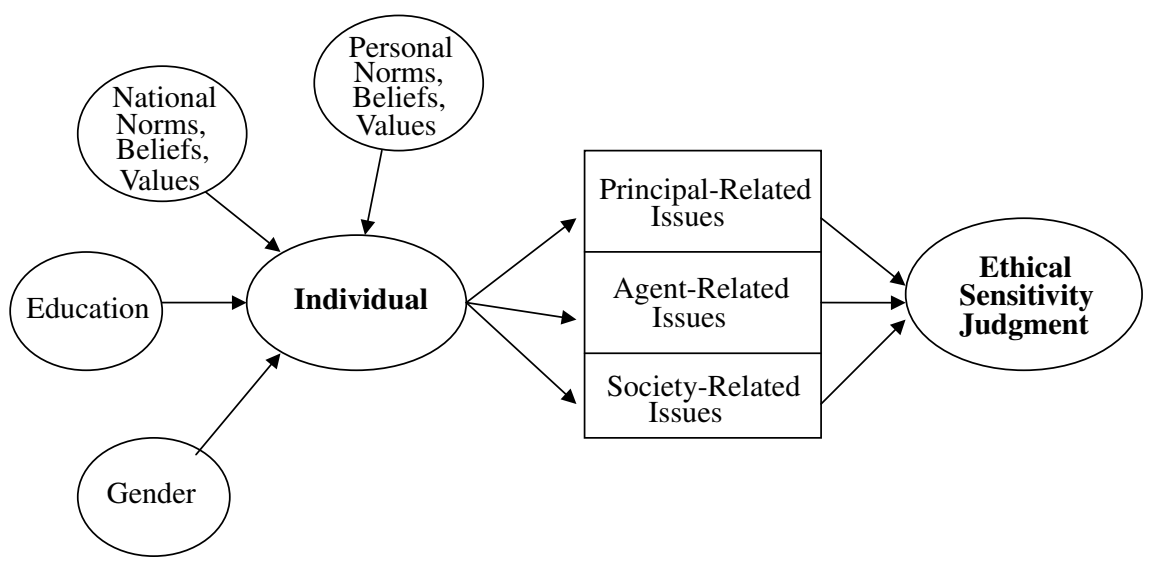

Figure 1. Proposed model of influences on ethical sensitivity judgments. Ethical perception or sensitivity of individuals judging the actions of other individuals relating to different issues is affected by the national and personal norms, values and beliefs as well as the educational background and gender. 
to principals, agents, and society or third parties, to influence the outcome of ethical decision processes. Specifically, the current study aims to empirically test whether ethical sensitivity regarding issues involving principals (i.e., clients or business owners), agents (i.e., employees), and society (i.e., third parties) differ between men and women and between two countries with contrasting economic conditions and cultural values, the U.S. and Turkey. Ethical dilemmas, in the form of vignettes, are used to present multi-faceted situations that deny predictability and resolution via the application of concrete rules (Dienhart, 1995; Thorne, 1998). Study participants evaluate the conduct described in the vignettes with respect to whether is it, or is not, ethical. Using experienced managers to evaluate ethical conduct in principal, agent and societal settings, this research examines potential gender and country differences in ethical sensitivity that may be role dependent.

\section{Theory and hypotheses}

\section{Contextual influences on ethical sensitivity}

An individual's ethical sensitivity involves four main elements. The first one is the existence of an ethical issue resulting from the actions of individual(s) or entity (entities) that may harm or benefit oneself or others (Velasquez and Rostantowski, 1985). The second element is the moral agent who performs the action. The third is the resulting ethical judgment that is substantially affected by the fourth element, moral intensity. Moral intensity is defined as "... a moral construct that captures the extent of issue related moral imperative in a situation ... and focuses on the moral issue not on the moral agent" (Jones, 1991, p. 372, 373). The tendency to perceive moral or ethical issues in business settings depends upon one's standards of right and wrong, moral and immoral conduct. Those standards are greatly affected by one's experiences at work and in personal life, one's professional training, and the social environment.

The ethical sensitivity of an individual is also affected by the moral intensity of the action. In his issue-contingent model, Jones (1991) theorizes that
“... six characteristics of the moral issue-magnitude of consequences, social consensus, probability of occurrence of the effect, temporal immediacy, proximity and concentration of effect ..." are positively related to moral decision making and behavior (p. 372). Magnitude is concerned with the severity of the consequences of an action. Social consensus depends upon the extent of agreement among stakeholders regarding social and legal opinions about the issue. Proximity refers to the physical, social or psychological closeness of the moral agent to the beneficiaries or the victims of the action. The greater the probability that the effect will be realized and the shorter the time between an action and its consequences, the more ethical sensitivity evoked. The degree to which conduct is perceived to have the potential of harming oneself or those with whom one can identify, because of similarities with oneself, will also influence one's tendency to identify the conduct as unethical.

Rettinger and Hastie (2001) empirically test domain effects on the decision-making process in general; their findings are similar to Jones (1991). Their results are that the "... content domain in which a decision problem occurs plays an important role in determining the decision outcome (p. 352)." They determine that the moral issues involved in a decision, along with the content, concreteness of the outcome, duration of the effect, and whether the outcome has direct impact on the decision maker influence the decision process.

\section{Ethical issues and agency theory}

Agency theory may be used as a model for discussing some of the roles that people occupy in business and the ethical duties and rights that accompany those roles (Boatright, 1992). The model of agent and principal used in the current study originates in the law of agency, which specifies the reciprocal rights and duties of agents and principals. An agency relationship arises when one person agrees to serve in place of, or act on behalf of, another (the principal). The agency relationship depends upon a publicly accepted system of rules that define the transactions that give rise to special rights and duties. People recognize and accept a system of conventions that 
specifies that by doing certain things (such as signing a paper) a person undertakes an obligation to do what he or she agrees to do (Velasquez, 1982, p. 64). Contractual rights and duties also provide a basis for the special duties or obligations that people acquire when they accept various roles or positions within legitimate organizations.

The relationship of agent and principal has an ethical dimension that is overlooked in the agency theory of economists. The ethical rights and obligations between contracting parties may be traced to Immanuel Kant (1724-1804). According to Kant, human beings possess certain moral rights and duties, regardless of any utilitarian benefits (aggregate social welfare) that the exercise of those rights and duties may provide for others (Velasquez, 1982, p. 65). Everyone has the right to be treated as a free person, equal to everyone else, and the corresponding duty to treat others in this way. Standards concerned with moral rights have greater weight than do utilitarian and justice standards. Moral rights identify areas in which other people, generally, may not interfere, even if they would derive greater benefits from such interference (Velasquez, 1982).

In legal theory, agency is created by a contract between consenting parties. The rights and duties arising from the contract attach to the specific persons who are parties to the contract. The system of rules that underlies contractual rights and duties includes several moral constraints.

1. Both of the parties to a contract must have full knowledge of the nature of the agreement they are entering,

2. Neither party to a contract must intentionally misrepresent the facts of the contractual situation to the other party,

3. Neither party to the contract must be forced to enter the contract under duress or coercion, and

4. The contract must not bind the parties to an immoral act (Velasquez, 1982, p. 65).

By freely entering into an agreement to act as another person's agent, one accepts a legal and moral duty to serve the principal loyally, obediently, and in a confidential manner (Velasquez, 1982, p. 19). Boatright (1992) shows that to exploit an agency relation for personal gain (conflict of interest) violates the bond of trust that is part of the agency relationship. An agent's duty of loyalty also constrains an agent from acquiring a competing interest or acting on behalf of others who are in competition with the principal (Section 394 of the Restatement of Agency, Boatright, 1992). An agent's obligation to a principal extends to confidentiality even after the agency relationship ends. For example, it is unethical for the president of a corporation to attempt a takeover of another company for which the president is a former director because the president may possess confidential information about the takeover target (Boatright, 1992).

However, the law of agency also specifies that the agent should determine whether the principal's orders are in accordance with business and professional ethics. If it is unethical for the principal to engage in certain activities, it is also unethical for the agent to do so. Thus, an agent is obliged to act on behalf of the principal only when such action is ethical. Only if one assumes that the above constraints advance self-interests, is the law of agency compatible with economic theory (Boatright, 1992).

An agent's duties to a principal also give rise to certain obligations on the principal's part. According to the rational model of business organizations, the business organization is a coordination mechanism designed to achieve some technical or economic goal with maximum efficiency (Schein, 1965). In this model, the employee is an agent who freely and knowingly agrees to accept the organization's formal authority and to pursue it goals in return for wages and fair working conditions (Velasquez, 1982, p. 304). Fair compensation, equal pay for equal work, and safe working conditions are basic moral obligations of employers to employees (Velasquez, 1982).

An alternative to the rational model of the firm is the political model. The firm is depicted as a system of competing power coalitions and of formal and informal lines of influence and communication (Cyert and March, 1963). Rather than focusing on contractual rights and obligations, under the political model of the firm, moral constraints revolve around the use of power within the organization. Through the law of agency and contract, influence on government agencies, and economic leverage, large 
corporations are granted the authority to exercise power over employees. Among the powers granted to employers are the powers to fire, demote, and promote employees. Similar to the civil rights that limit government power over citizens, managerial power over employees is limited by moral constraints. Employees have the right to privacy, due process, the right to consent, freedom of speech, etc. (Velasquez, 1982).

These theories of the firm give low priority to public and third party interests (Gibson, 2000). By definition, the general public and individual third parties (those not explicitly identified as parties to the contract) have no contractual duties or rights because they are not parties to the contract. According to agency theory, to extend an agent's duties to third parties or society would make the agent responsible to a class of unknown identity and size, for an indeterminate time period. Such an extension is at odds with the premise that agents are responsible for only the known and intended consequences of their free actions. Exceptions to moral culpability for lack of knowledge and inability to perform are a viable defense to claims of harm made by third parties (Velasquez, 1982).

In contrast to the above, under the distributive theory of justice, business enterprises have extensive moral responsibilities to society and individual third parties. Distributive theories consider the distribution of society's benefits and burdens. The distribution problem arises because individual members of society make competing claims to the advantages of social cooperation (Lessnoff, 1986). The principles of distributive justice are that,

(1) Basic liberties must be fully enjoyed by all equally (unless an unequal distribution of these liberties improves the total basic liberty of those who have less);

(2) There must be fair equality of opportunity for all to achieve desired social and economic positions (unless unequal opportunity either improves the opportunities of those with fewer opportunities, or improves their basic liberties); and

(3) Inequalities in other social and economic primary goods (income, wealth, power, authority) must be such as to benefit most those who have least of them (Lessnoff, 1986).
Basic liberties include, among others, the right to vote, freedom of speech, freedom to hold personal property, and freedom from arbitrary arrest (Lessnoff, 1986). Under the distributive theory of justice, these liberties imply that businesses should not invade one's privacy, pressure employees to vote a certain way, or violate the civil liberties of any of society's members (Velasquez, 1982). Transactions with customers, including advertising, should be free from deception. It is also unjust for businesses to pollute our air or water, sell defective or dangerous products, or act in ways that may harm future generations. The distributive theory of justice depicts an ideal that is seldom realized by individuals organized to produce goods and services in capitalist economies.

Ethical judgments are theorized to depend upon internalized moral standards. The tendency to perceive moral or ethical issues in business settings depends upon one's standards of right and wrong, moral and immoral conduct. Those standards are greatly affected by one's experiences. The participants in the current study were business executives and managers. Many were in middle management positions in which they served as agents of the various business entities that employed them. Those participants who were in upper level management positions or who owned businesses were principals, relative to their employees. With respect to the clients they served in their positions as accountants, financial advisors, bankers, etc., they were also agents.

It is our hypothesis that business managers and executives evaluate ethical dilemmas from their perspectives as agents. All other things being equal, we expect business people are most sensitive to unethical conduct in situations in which there is a potential of harm to agents (those perceived as similar to themselves). The differences in ethical sensitivity that we predict are based on the research that shows that people are more sensitive to potential wrongs to themselves than they are wrongs to others. Potential injuries or infringements on one's own rights are more salient than is harm to others (Kohlberg, 1976; Piaget, 1965). With respect to Jones' theory of moral intensity, ethical dilemmas involving potential wrongs to oneself or those with whom one may identify possess moral intensity (Jones, 1991).

Duties owed by agents to principals will be in second place in terms of perceptions of unethical 
conduct. This prediction is also consistent with Kohlberg's theory of ethical development (Kohlberg, 1976). Satisfying the expectations of peers is of great importance to people at the conventional stage of moral development. Concern with fulfilling responsibilities to principals would arise at this stage of moral development. The norms associated with the role of agents are conveyed through professional codes of conduct, corporate policies, and interactions among employees (Gibson, 1999; Hunt and Vitell, 1986; Jones, 2001; Velasquez, 1982). These norms may increase the moral intensity of an ethical dilemma; however, they are not as powerful as the moral intensity provoked by a threat to oneself.

Ethical sensitivity to third parties or society's interests is lower than ethical sensitivity to the interests of agents and principals. Third parties and society are distant, unseen, and removed from direct contact (Jones, 1991). When third parties and the general public are harmed, it is often difficult to assign responsibility to an individual or group of people acting intentionally. Instead, the harm is often regarded as an unintended consequence of industrial development, technology, or business competition (Gibson, 1995).

In the study reported here, ethical dilemmas were posed to business managers and other professionals. These dilemmas involved potential conflicts of interest between individuals and their employers or principals (those for whom one acts as an agent) and between the individuals and unidentified third parties or society as a whole. A participant's ethical sensitivity was inferred based upon his or her evaluation of the dilemmas. The hypotheses stated in the alternative form are the following:

H1: Ethical sensitivity is highest when the interests of agents (those similar to oneself) are at stake.

H2: Ethical sensitivity of agents is higher when the interests of principals, as compared to third parties or society, are at stake.

\section{Nationality and gender effects}

The U.S. and Turkey differ from each other on power distance as well as individualism versus collectivism dimensions as these terms were defined by Hofstede
(1991). On the power distance index higher values signify large power distance. The U.S. scores 40, compared to Turkey's score of 66. People in a high power distance culture "expect and accept" that power is distributed unequally (Hofstede, 1991, p. 28). On the individualism versus collectivism index, higher scores represent individualistic attitudes, i.e., caring for oneself or one's immediate family, with less concern for the well being of one's community. With a score of 91, U.S. is the most individualistic nation studied, while Turkey displays a collectivist orientation with a score of 37 (Hofstede, 1991).

In a study investigating the reasons for moral judgments in six countries, French and Weis (2000) characterized Turkey as a county where group affiliation is very strong and the members of a group are expected to provide for and protect each other. These findings assert that the Turks rely on "honesty: as a reciprocal obligation/right (within group)", whereas the Americans value "equity: based on reciprocity (with anyone)" more than any other trait in solving their ethical disputes (French and Weis, 2000, p. 132). Thus, when faced with ethical decisions, Americans utilize "ethics of justice," and Turkish people resort to "ethics of care".

In a 34-country study, Turkey is reported to be above average in the cultural values of conservatism and hierarchy (Schwartz, 1994). In-group collectivism is higher in Turkey than in the U.S. Turkish managers show more loyalty toward their peers, family and organizations (Aycan et al., 1999; Aycan et al., 2000). Similarly, Fikret-Pasa et al. (2001) find that the ideal leadership qualities reflect high power distance and assertiveness, along with collectivism.

In a comprehensive review of how and why cultural differences arise, Jackson (2001) developed and tested a model of ethical decision-making in 10 countries. His results imply that American managers, who are viewed as having individualistic traits and low uncertainty avoidance, put more emphasis on ethical issues that relate to external stakeholders than they do on issues regarding organizational concerns. Along similar lines, Tsalikis et al. (2002) examined ethical perceptions of two scenarios involving immoral acts in Greece and the U.S. They found that gender was not an important factor and that national characteristics had a significant effect. 
Thus we hypothesize business managers from the U.S. and Turkey will display different ethical sensitivity regarding the issues investigated and state the alternative form of the hypothesis as follows:

H3: There are differences between those of U.S. and Turkish nationalities in ethical sensitivity to principal, agent and society-related issues.

Collins (2000) provides an excellent review of prior empirical research on the relationship of gender and ethical judgments, revealing disparities in the findings. Some studies report that women, compared to men, are more cautious and more concerned about ethical issues in general and business ethics in particular. Among the studies that reported that women exhibit higher moral development are these: Arlow (1991), Ameen et al. (1996), Beltramini et al. (1984), Coate and Frey (2000), Cohen et al. (1998), Cole and Smith (1996), Crow et al. (1991), Galbraith and Stephenson (1993), Harris and Sutton (1995), Jones and Gautschi II (1988), Kidwell et al. (1987), Larkin (2000) McCabe et al. (1991), Miesing and Preble (1985), Peterson et al. (1991), Poorsolton et al. (1991), Ruegger and King (1992).

However, other studies report no significant gender differences in ethical judgments on social or business issues (e.g., Barnett and Karson, 1989; Davis and Welton, 1991; Dubinsky and Levy, 1985; Harris, 1989; Hegarty and Sims, 1978, 1979; McNichols and Zimmerer, 1985; Radtke, 2000; Tsalikis and Ortiz-Buonafina, 1990). A potential explanation for the seemingly contradictory results of extant research is the supposition that gender differences may or may not arise, depending upon context-specific factors (Derry, 1987, 1989; Dobbins and Platz, 1986; Trevino, 1992; Weber, 1990). In particular, established professional norms and roles may lead both men and women to think in certain ways, in particular contexts (Goodpaster, 1991; Quinn and Jones, 1995).

As stated above, some research found differences between the genders and other research found no difference, especially in cases related to professional contexts. Thus, our last hypothesis is that there will be differences between genders in some contexts, although not in all three (agent, principal, and society). The hypothesis is the following:
H4: There are differences between men and women in ethical sensitivity to principal, agent and society-related issues.

\section{Method}

Participants

All respondents in the current study were professionals with diverse educational backgrounds working at different management levels in organizations. Participants were university graduates with degrees from engineering, business, economics, health, or public relations. Initially, a total of 171 professionals participated in the study. Nine of the Turkish professionals and two of the U.S. professionals had doctoral degrees. Their responses were eliminated from the analysis because of studies indicating that higher education levels may be associated with increased ethical sensitivity and such heterogeneity in educational backgrounds may confound the ethics judgments (Rest, 1986).

As depicted in Table I, 57 (36\%) of the remaining respondents were from the U.S. and 103 (64\%) from Turkey. Approximately $45 \%$ of the Turkish

TABLE I

Demographic information

\begin{tabular}{|c|c|c|c|c|c|c|}
\hline & \multicolumn{2}{|c|}{$\begin{array}{l}\text { All } \\
(n=160)\end{array}$} & \multicolumn{2}{|c|}{$\begin{array}{l}\text { Turkish } \\
(n=103)\end{array}$} & \multicolumn{2}{|c|}{$\begin{array}{l}\text { U.S. } \\
(n=57)\end{array}$} \\
\hline & $n$ & $(\%)$ & $n$ & $(\%)$ & $n$ & $(\%)$ \\
\hline \multicolumn{7}{|l|}{ Gender } \\
\hline Female & 64 & 40.0 & 46 & 44.7 & 18 & 31.6 \\
\hline Male & 96 & 60.0 & 57 & 55.3 & 39 & 68.4 \\
\hline \multicolumn{7}{|l|}{ Age } \\
\hline Less than 30 & 126 & 78.8 & 84 & 81.6 & 42 & 73.7 \\
\hline $31-40$ & 28 & 17.5 & 16 & 15.5 & 12 & 21.1 \\
\hline 41 or older & 6 & 3.8 & 3 & 2.9 & 3 & 5.3 \\
\hline \multicolumn{7}{|l|}{ Position } \\
\hline Upper managerial & 51 & 31.9 & 33 & 32.0 & 18 & 31.6 \\
\hline Lower managerial & 109 & 68.1 & 70 & 68.0 & 39 & 68.4 \\
\hline \multicolumn{7}{|l|}{ Work experience } \\
\hline Less than 5 years & 109 & 68.1 & 83 & 80.6 & 26 & 45.6 \\
\hline $6-11$ years & 38 & 23.8 & 16 & 15.5 & 22 & 38.6 \\
\hline More than 11 years & s 13 & 8.1 & 4 & 3.9 & 9 & 15.8 \\
\hline
\end{tabular}


participants and $32 \%$ of the U.S. respondents were female. The average ages of the participants from the U.S. and Turkey were 29 and 27, respectively. Sixty-eight percent of respondents held lower managerial positions, while $32 \%$ held upper managerial positions. Although the U.S. participants reported more work experience than the Turkish participants, their positions were quite similar.

TABLE II

Summary of vignettes

Vignette 1 (Agent): Employer insists that a new marketing manager divulge competitive information about her former employer.

Vignette 2 (Principal): Deliberate omission of a subsequent event. Company management omits information about a planned acquisition from its financial statements and the auditor, knowing this, issues an unqualified opinion.

Vignette 3 (Principal): Informing on a competitor. Knowing how sensitive he is about such matters, a female auditor tells the president of the company that was once her audit client that she saw an "illegal" document in the apartment of the male auditor, who is the new auditor from a competing firm.

Vignette 4 (Principal): Failure to inform one's supervisor. After verifying management's claim that everyone in the business pays "kickbacks" to get their records played on the radio, staff accountant fails to inform anyone in his firm about the irregular payments he discovered during an audit.

Vignette 5 (Principal): Failure to inform client of one's own conflict of interest. Partner in charge of an audit finds out that his father-in-law's company has loaned money to a new business that has received a major contract from the auditor's client. He believes the new firm is inexperienced but says nothing to the client. A bribe is implied to be forthcoming from the father-inlaw's company.

Vignette 6 (Agent): Forced retirement as a consequence of an error. A female partner, after learning that a male partner who has health problems omitted an audit procedure in a recent audit, talks to the other partners and requests that the auditor resign from the firm.

Vignette 7 (Society): Gender equity in hiring favors the male. To achieve greater gender equity, in line with company wishes, a woman recommends a male applicant
TABLE II

(Continued)

for a secretarial position even though she prefers the female applicant (both applicants are qualified).

Vignette 8 (Society): Bypassing mandated water treatment to save money. Management decides to by-pass secondary water treatment to save money and improve upon the operation of its air conditioning equipment.

Vignette 9 (Principal): Breach of client confidence. Auditor divulges confidential information about one client to another client.

Vignette 10 (Principal): Retaining client property in billing dispute. Advertising executive, whose client is disputing billing rates on a recent job, keeps property the client had loaned to him.

Vignette 11 (Agent): Exclusion of female employee from client meeting at men's club. When he learns that the client plans to take them to a men's-only club, the regional manager of an audit firm drops his plan to include a female auditor in the client meeting.

Vignette 12 (Society): Failure to inform customers of untested chemical. Management learns that a chemical used in processing a raw material used pharmaceutical and cosmetic products has not been tested for its effect on humans. The company discontinues its use of the chemical, but does not inform existing customers who may have purchased the product.

Vignette 13 (Society): Earnings forecast based on questionable assumptions. Before releasing her earnings forecast, a Parsona employee learns that their supplier will be unable to meet the demand for a raw material that Parsona needs. Knowing this will impact Parsona's sales, she tells her supervisor. On his advice, she publishes the original forecast.

Vignette 14 (Agent): Demotion after maternity leave. An employee returns from maternity leave and finds that management has assigned her to a new job with less responsibility and promotion potential. The employer justifies the appointment on the basis that there is no guarantee that she will not get pregnant again.

Vignette 15 (Society): Unsubstantiated product safety rumors ignored. Rumors about a food additive indicate that it may cause cancer. Since the FDA has not prohibited the use of the additive and has no evidence that it may be harmful, the food engineer continues to use it. He knows of an available substitute, but it is very expensive.

Vignette 16 (Agent): Reaction to office affair. A coworker learns about an inter-office affair between two auditors and demands that management intervene to end the affair. Evaluate the co-worker's behavior. 


\section{Ethics vignettes}

The 16 vignettes used in the current study constitute a subset of the vignettes that were used to examine the ethical sensitivity of Turkish business students in a previous study (Simga-Mugan and Onkal-Atay, 2003). Based on the results of that study, the 16 vignettes were selected because of their discriminating power. The authors classified the vignettes into principal, agent and societal categories based upon the party (principal, agent, or society) whose interests were potentially compromised by the action depicted in the scenario. Descriptions of the vignettes are presented in Table II.

Each vignette involves a specific ethical dilemma that reflects a realistic conflict situation leading to a questionable action performed by an individual described in the scenario. Special care was taken to select vignettes depicting situations that would be familiar to professionals in both cultures. The vignettes were pre-tested to assure sufficient detail in representing realistic situations, while avoiding unduly complex scenarios. Another problem encountered in ethical judgment studies is the social desirability bias that is introduced when respondents provide answers that they believe are socially acceptable. Earlier research found that such bias is reduced when the respondent is the observer (Jackson, 2001; Sinha and Verma, 1987; Verma, 1992). Thus, the vignettes were designed to ask for the respondent's opinion regarding the conduct in the scenario.

All the scenarios depicted conduct that, at the least, was potentially unethical because it benefited one stakeholder at the expense of another. After reading each scenario, respondents indicated their assessments of the conduct depicted by marking a number from 1 to 7 on a Likert scale. Marking 1 indicated a judgment that the conduct was perceived to be definitely ethical, while a marking of 7 showed the conduct was perceived as definitely unethical. Ethical sensitivity is defined as the tendency to judge the conduct unethical, thus higher scores are associated with greater ethical sensitivity.

Language differences were one of the caveats in earlier work involving participants from different countries. To overcome that problem, vignettes were presented in the native tongue of the respondents. All vignettes were cross-translated and pre-tested to en- sure that they conveyed the same message in both languages to avoid any interpretation variations.

\section{Data analysis}

The first step in analyzing the data was to conduct paired-comparison $t$-tests of the means by individual factors predicted to influence ethical sensitivity. These tests are a measure of the statistical significance of the separate factors, such as gender, on the responses. However, multivariate analysis was required to determine the impact of any single factor in the presence of all the other factors that influence the ethical judgment. Repeated measures MANCOVA tests were conducted using Type III sums of squares. Repeated measures analysis, rather than individual $t$-tests, was appropriate because the responses to 16 different vignettes were within subject measures of ethical sensitivity. Type III sums of squares are invariant to differences in cell frequencies (unbalanced designs), and the sums of squares of an effect is calculated as the sums of squares adjusted for any other effects that do not contain it and orthogonal to any effect(s) that contain it. This analysis is appropriate when interaction effects are expected, as they were in our study. Nationality (Turkish or U.S.) and gender were between subject variables, and the 16 vignettes were within subject variables. Initial analysis of the data indicated that there were several auditors in the Turkish sample and only two in the U.S. sample. To control for the potential effect of this occupation on ethical judgments, auditor (coded as 1 for auditors, and zero otherwise) was treated as a covariate (Tabachnick and Fidell, 1996).

\section{Procedure}

The printed questionnaires were delivered to the human relations departments of companies in Turkey to be distributed to managers at various levels. Professionals were also recruited via announcements on the alumni network of a comprehensive university in Turkey, where the questionnaires were sent to the volunteers by electronic mail. Overall, the response rate was about $30 \%$. The questionnaires were collected after one week, either personally or by electronic mail. In the 
U.S., the respondents were professional or executive MBA students from a comprehensive public university in the northeast. Both groups were full time managers pursuing graduate degrees. The questionnaires were distributed to the executive MBAs through the college's administrative office, and they were personally administered to the professional MBA students by the first author in class. The overall response rate was around 50\%. In both countries participation was voluntary and anonymity was assured.

Participants were informed that they would read 16 scenarios about ethical dilemmas that may arise in work situations and that they would be asked their 'opinions' regarding the conduct in these scenarios. Exit interviews with MBA students confirmed our expectation that the respondents stated their honest opinions in answering the questions.

\section{Results and discussion}

Table III reflects that among the three categories of vignettes, the agent-related issues evoked the highest ethical sensitivity (only $25.7 \%$ of responses were in the ethical range), followed by sensitivity toward principals, and societal issues. In paired comparison $t$-tests using the Bonferroni adjustment for multiple comparisons, the mean differences among responses grouped by agent, principal, and societal subject matter were statistically significant at $p<0.001$. This finding supports rejection of the null hypotheses of no differences in ethical sensitivity based upon the entity affected, agent, principal, or society. This is consistent with our expectations as stated in $\mathrm{H} 1$ and $\mathrm{H} 2$.

Overall 16 vignettes, females were more sensitive than males. In $27.5 \%$ of the female responses, the actions depicted were rated ethical if 1, 2, or 3 was marked on the Likert scale. Among males, $33.2 \%$ of the responses were in the above range. In a $t$-test, the mean difference between the average responses to the 16 vignettes by men and women was statistically significant, providing support for our fourth hypothesis that gender influences ethical sensitivity $(t=3.121, p<0.10)$. Detailed results are reported in the discussion in subsequent sections of responses to the vignettes within the agent, principal, and societal contexts.

TABLE III

Ethical sensitivity descriptive results

\begin{tabular}{|c|c|c|c|c|}
\hline & Mean $^{\mathrm{a}}$ & Ethical (\%) & Neutral (\%) & Unethical (\%) \\
\hline \multicolumn{5}{|l|}{ Gender $^{b}$} \\
\hline Female & 4.742 & 27.5 & 12.8 & 59.7 \\
\hline Male & 4.544 & 33.2 & 11.8 & 55.0 \\
\hline \multicolumn{5}{|l|}{ Country $^{c}$} \\
\hline U.S. & 4.448 & 34.6 & 10.3 & 55.1 \\
\hline Turkey & 4.727 & 28.8 & 13.2 & 58.0 \\
\hline \multicolumn{5}{|l|}{ Vignettes $^{\mathrm{d}}$} \\
\hline Principal & 4.794 & 29.0 & 12.1 & 58.9 \\
\hline Agent & 4.931 & 25.7 & 11.0 & 63.3 \\
\hline Society & 4.221 & 38.3 & 13.4 & 48.3 \\
\hline \multicolumn{5}{|l|}{ Female } \\
\hline U.S. & 4.609 & 26.5 & 13.2 & 60.3 \\
\hline Turkey & 4.797 & 30.1 & 11.5 & 58.4 \\
\hline \multicolumn{5}{|l|}{ Male $^{c}$} \\
\hline U.S. & 4.381 & 30.7 & 13.2 & 56.1 \\
\hline Turkey & 4.668 & 36.7 & 9.8 & 53.5 \\
\hline
\end{tabular}

\footnotetext{
a Arithmetic mean: not adjusted for covariate.

${ }^{b}$ Mean difference significant at $p<0.10$.

${ }^{c}$ Mean difference significant at $p<0.05$.

${ }^{\mathrm{d}}$ Paired comparison $t$-tests significant at $p<0.001$.
} 
TABLE IV

Multivariate tests ethical sensivity

\begin{tabular}{llrllll}
\hline Effect & Value & $F$ & \multicolumn{2}{l}{$\begin{array}{l}\text { Hypothesis } \\
\text { df }\end{array}$} & $\begin{array}{l}\text { Error } \\
\text { df }\end{array}$ & Sig \\
\hline Vignette & 0.291 & 21.082 & 15 & 130 & 0.0001 \\
Vig*Auditor & 0.857 & 1.445 & 15 & 130 & 0.136 \\
Vig*Gender & 0.797 & 2.202 & 15 & 130 & 0.009 \\
Vig* $_{\text {Nationality }}^{*}$ & 0.75 & 2.887 & 15 & 130 & 0.001 \\
Vig*Gender* & 0.837 & 1.694 & 15 & 130 & 0.060 \\
Nationality & & & & & \\
\hline
\end{tabular}

Based on Wilks' Lambda.

Design: Intercept + Auditor + Gender + Nationality + Gender * Nationality.

Within subject: Vignette (Vig) $n=16$.

Country comparisons reflect that Turkish participants made fewer responses in ethical range (1-3) than did the U.S. respondents, 28.8 and $34.6 \%$, respectively. The difference between the means by nationality is significant $(t=5.904, p<0.05)$. Although differences between females from the two countries are not significant, Turkish males are more ethically sensitive than their U.S. counterparts $(t=$ 4.080, $p<0.05)$. Again, these findings provide support for $\mathrm{H} 3$ that nationality will lead to differences in ethical sensitivity.

As reported in Table IV, statistically significant differences were found on the multivariate $F$-tests of Vignette (Vig), Vignette by Gender, and Vignette by Nationality. The Vignette by Auditor interaction was not statistically significant $(p=0.136)$. These results indicate that ethical sensitivity judgments depend upon interactions between vignette, gender, and nationality.

\section{Vignettes categorized by subject matter}

To further understand the interaction effects, additional analyses, with auditor as a covariate, were conducted on the vignettes categorized by subject matter. As summarized in Table II, six vignettes dealt with ethical dilemmas involving duties to clients (principals), five vignettes with dilemmas involving duties to employees (agents), and five with duties to third parties (society). Paired comparisons among the mean responses, adjusted for the auditor covariate, to the principal, agent, and society classifications of the vignettes indicate that vignettes involving agent-related issues evoke the highest ethical sensitivity $(M=5.030$, S.D. $=0.085)$, followed by principals $(M=4.657$, S.D. $=0.083)$, and then society $(\mathrm{M}=4.174$, S.D. $=0.087)$. Differences among these means are all statistically significant (all $p<0.001)$.

These findings support our first and second hypotheses. Respondents show the highest ethical sensitivity to issues that affect agents, H1. They also show higher ethical sensitivity to issues affecting principals than to societal issues, $\mathrm{H} 2$.

The display of highest sensitivity to ethical dilemmas involving responsibilities to agents is consistent with the Jones (1991) model. It may be that the participants identify with the actors described in the vignettes and that they believe that they could be affected by similar dilemmas. In other words, the moral intensity of the issues is greater in the agentrelated vignettes. Another factor, as suggested by Jones (1991), may be the certainty of the effect in the vignettes. There is a specific action in each vignette. When one knows the outcome and the magnitude of the event, one becomes ethically more sensitive.

These results confirm Kohlberg's (1976) proposition that most people operate at the conventional stage of moral development in which their peers' judgments and acceptance by the group are their benchmark for proper conduct. The results are also consistent with Ponemon's work showing that accountants were at the conventional stage of ethical reasoning (Ponemon, 1992). Thus, we may conclude that the respondents in the current study operate at the conventional level.

Given the significant differences among the three categories of vignettes, repeated measures analyses (with auditor as a covariate) were conducted to determine the effects of gender and nationality in each of the three categories. These results are reported by the category of the vignettes, in descending order: (1), ethical sensitivity with respect to responsibilities to agents, (2), to principals, and (3), to society.

\section{Responsibilities to agents}

The repeated measures multivariate tests with respect to responsibilities to agents indicated statis- 
TABLE V

Ethical sensitivity vignettes involving duties to agents

\begin{tabular}{|c|c|c|c|c|c|c|}
\hline Effect & Value & $F$ & & Hypothesis df & Error df & Sig \\
\hline \multicolumn{7}{|l|}{ Panel 1} \\
\hline Vignette & 0.529 & 33.590 & & 4 & 151 & 0.0001 \\
\hline Vig*Auditor & 0.984 & 0.622 & & 4 & 151 & 0.647 \\
\hline Vig*Gender & 0.919 & 3.316 & & 4 & 151 & 0.012 \\
\hline Vig*Nationality & 0.933 & 2.729 & & 4 & 151 & 0.031 \\
\hline $\begin{array}{l}\text { Vig*Gender*Nationality } \\
\text { based on Wilks' Lambda }\end{array}$ & 0.975 & 0.983 & & 4 & 151 & 0.419 \\
\hline \multicolumn{7}{|c|}{$\begin{array}{l}\text { Design: Intercept }+ \text { Auditor }+ \text { Gender }+ \text { Nationality }+ \text { Gender } * \text { Nationality. } \\
\text { Within subject: (Vig) Vignettes 1, 6, 11, } 14 \text { and } 16 .\end{array}$} \\
\hline Dependent variable & Gender & & Mean & S.E. & & Sig \\
\hline \multicolumn{7}{|c|}{ Panel 2: Vignettes with significant between subject effects for gender } \\
\hline \multirow[t]{2}{*}{ Vig 1} & $\mathrm{~F}$ & & 4.690 & 0.261 & & \multirow[t]{2}{*}{0.006} \\
\hline & M & & 3.775 & 0.199 & & \\
\hline \multirow{2}{*}{$\operatorname{Vig} 6$} & $\mathrm{~F}$ & & 4.964 & 0.283 & & \multirow[t]{2}{*}{0.078} \\
\hline & M & & 4.335 & 0.215 & & \\
\hline \multirow{2}{*}{ Vig 11} & $\mathrm{~F}$ & & 5.041 & 0.278 & & \multirow[t]{2}{*}{0.0001} \\
\hline & $\mathrm{M}$ & & 3.673 & 0.211 & & \\
\hline \multirow[t]{2}{*}{ Vig 14} & $\mathrm{~F}$ & & 6.656 & 0.198 & & \multirow[t]{2}{*}{0.009} \\
\hline & M & & 5.999 & 0.150 & & \\
\hline Dependent variable & Nationality & & Mean & S.E. & & Sig \\
\hline \multicolumn{7}{|c|}{ Panel 3: Vignettes with significant between subject effects for nationality } \\
\hline \multirow[t]{2}{*}{ Vig 11} & Turkish & & 3.889 & 0.233 & & \multirow[t]{2}{*}{0.035} \\
\hline & U.S. & & 4.825 & 0.329 & & \\
\hline
\end{tabular}

F: female, $n=64, \mathrm{M}$ : male, $n=95$.

Nationality: Turkish, $n=102$, U.S., $n=57$.

Covariate is evaluated at Auditor $=0.41$.

Means are estimated marginal means.

Bonferroni adjustment made for multiple comparisons.

tically significant differences among Vignette, Vignette by Gender, and Vignette by Nationality ( $p$ values of $0.0001,0.012$ and 0.031 , respectively, Table V: panel 1). In between subject tests of the model, gender was statistically significant, $\quad(F=14.106$, $p<0.0001)$. With respect to ethical sensitivity to dilemmas involving agents or employees, women appear to be more sensitive than men $(M=5.342$, S.D. $=0.131 \quad$ and $\quad M=4.717, \quad$ S.D. $=0.103$, respectively). Table V: panel 2 reports the statistically significant differences between men and women among individual vignettes depicting agent issues. This result supports our fourth hypothesis. It is also consistent with previous research, especially in the organizational context. One possible explanation for this result may lie in the rules females and males utilize in reaching ethical judgments, i.e., females are argued to typically utilize ethics of care, which emphasizes social virtues and caring for others. On the other hand, males are found to utilize ethics of justice, emphasizing equal treatment and playing by the rules.

Two vignettes, 11 and 14, involve possible discrimination against women. Consistent with Jones (1991) and Kohlberg (1976), the female respondents may have shown higher levels of ethical sensitivity because they could imagine themselves or their female peers in similar situations. The male 
respondents may not be as sensitive to potential discrimination against the other sex, because they may not identify with the actors in these vignettes and cannot imagine themselves in such situations.

The only vignette in which there were significant differences between nationalities was number 11 (Table V: panel 3, $p<0$.05). Vignette 11 depicts the exclusion of a female employee from a meeting organized by the client because the meeting will be held at a club that prohibits women guests. Turkish participants regard the behavior as more ethical than did the U.S. participants, resulting in lower ethical sensitivity for the Turkish participants. Hofstede's (1991) individualism-collectivism dimensions may explain the national differences. According to the individualism-collectivism index, Turkey is on the lower end of the scale with a score of 37 (pp. 52-54) representing a nation with strong collectivist traits. In

TABLE VI

Ethical sensitivity vignettes involving duties to principals

\begin{tabular}{lccccc}
\hline Effect & Value & $F$ & Hypothesis df & Error df & Sig \\
\hline Panel 1: Repeated measures MANCOVA & & & & \\
Vignette & 0.894 & 3.421 & 5 & 145 & 0.006 \\
Vig*Auditor & 0.954 & 1.387 & 5 & 5 & 0.233 \\
Vig*Gender & 0.984 & 0.462 & 5 & 145 & 0.804 \\
Vig*Nationality & 0.912 & 2.807 & 5 & 145 & 0.019 \\
Vig*Gender*Nationality & 0.924 & 2.381 & 5 & 145 & 0.041
\end{tabular}

based on Wilks' Lambda

Design: Intercept + Auditor + Gender + Nationality + Gender $*$ Nationality.

Within subject: (Vig) Vignettes 2-5, 9 and 10.

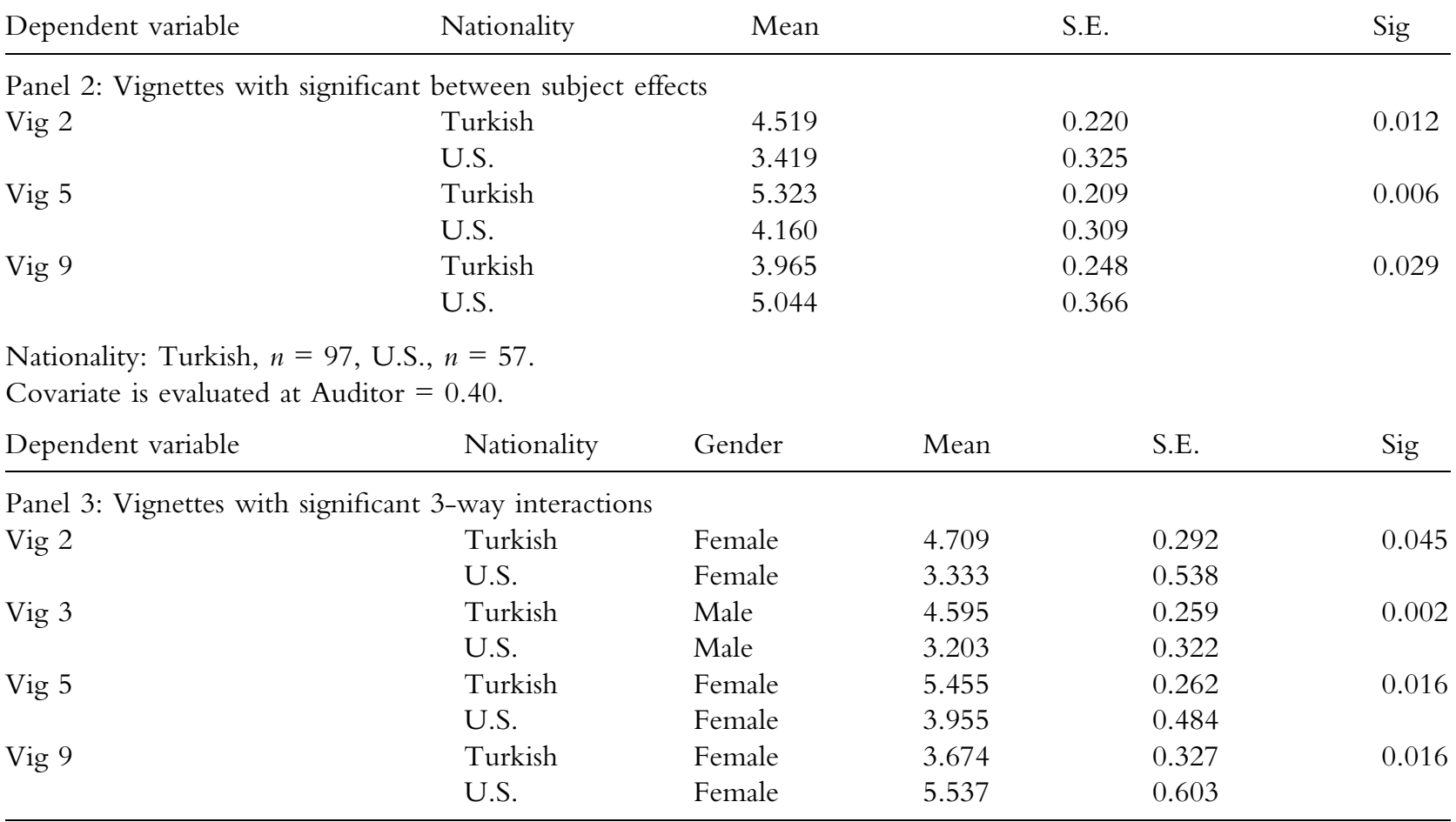

For females, covariate is evaluated at Auditor $=0.53$.

For males, covariate is evaluated at Auditor $=0.28$.

Means are estimated marginal means.

Bonferroni adjustment is made for multiple comparisons. 
contrast, the U.S. is the most individualistic country with a score 91 and a rank of 1 (Hofstede, 1991, pp. $52-54)$. The opportunity to socialize with one's clients, even though the female employee was excluded, may be more important to Turkish participants $(\mathrm{M}=3.889$, S.D. $=0.233)$, than to the U.S. respondents $(\mathrm{M}=4.825$, S.D. $=0.329)$. Previous research on human resource management supports this explanation. In-group-collectivism and personal relations among peers are stronger in Turkish organizations than in the U.S. (Aycan et al., 1999; Aycan et al., 2000). Moreover, the steep hierarchy and acceptance of the superiors' decisions in the Turkish organizations, as found in other studies might be a contributing factor (Ronen, 1986; Trompenaars and Hampden-Turner, 1998). Another interpretation may be that Turkish men and women are not as sensitive to the exclusion of the female employee, as are the U.S. respondents, because of the greater emphasis on gender equity issues in the U.S.

\section{Responsibilities to principals}

The analyses of ethical sensitivity with respect to responsibilities to principals or clients resulted in statistically significant differences in Vignette, Vignette by Nationality, and Vignette by Gender by Nationality (Table VI: panel 1) providing support for the third and fourth hypotheses that gender and nationality will lead to different levels of ethical sensitivity. Among the between subject tests, the result for Nationality $(F=3.627, p<0.059)$ warranted further investigation. The ethical sensitivity in dilemmas involving responsibilities to principals suggests that Turkish respondents are more sensitive than U.S. respondents $(\mathrm{M}=4.886, \quad$ S.D. $=0.107$ and $\mathrm{M}=4.486$, S.D. $=0.155$, respectively). The observed difference between the nationalities may be attributable to Hofstede's (1991) power distance dimension and moral reasoning processes. Regarding the power distance dimension which is defined as recognition and acceptance of unequal distribution of power, the U.S. and Turkey are on the opposite ends of the dimension (Turkey with 66 points and the U.S. with 40 points, where higher values denote higher power distance). Research in human resource management and leadership qualities indicates that hierarchy and power inequality find more acceptance in Turkey than the U.S. This results in more centralized decision-making and acceptance of rules and regulations imposed by superiors (Aycan et al., 1999; Aycan et al., 2000; Trompenaars and Hampden-Turner, 1998). The power distance dimension suggests that the agent will conform to the rules of the authorities and duties to principals, rather than pursuing self-interests.

Following this framework and relating it to ethics of care and ethics of justice arguments outlined previously, another possible explanation of the findings emerges. Western cultures, such as the U.S., which has a score of 62 on Hofstede's masculine versus feminine dimension, have been characterized as masculine, reinforcing achievement, competition and success (Hofstede, 1991). Ethics of justice utilized by the U.S. promotes freedom of choice and reciprocity based on low power distance to achieve success (French and Weis, 2000). On the other hand, Turkey scores relatively lower (i.e., 45, Hofstede, 1991), displaying more feminine cultural values that reinforce cooperation, establishing good relations with superiors, and conforming to the expectations of authorities. Consistent with these relatively feminine traits, Turkey is found to use ethics of care in resolution of ethical conflicts (French and Weis, 2000).

The significant differences between nationalities on the individual vignettes in this category suggest that the differences are greater than one might conclude on the basis of the difference between overall means. This is because, on Vignettes 2 and 5, Turkish respondents are more ethically sensitive, but, on Vignette 9, U.S. respondents are more ethically sensitive (Table VI: panel 2). None of the other between-subject effects is statistically significant. Examination of individual vignettes in which the U.S. and the Turkish respondents display their ethical sensitivity, support the explanation provided to account for the differences between the countries. In Vignettes 2 and 5, the Turkish respondents conform to the superiors' or authorities' expectations of them, displaying their ethics of care approach, and obeying the "authority" in the vignettes, consistent with the acceptance of power distance. On the other hand, the U.S. participants display ethics of justice reasoning in their responses to Vignette 9. The U.S. respondents, based on the principles of justice and 
individualism, perceive the breach of confidence in Vignette 9 as more unethical than do the Turks. In contrast, one may view the Turkish respondents as probably judging this vignette based on the ethics of care, thereby protecting one client's welfare by providing information about another client, with whom the first client has business relations.

In Table VI: panel 3, vignettes associated with the statistically significant effects on the three-way interaction between vignette, gender, and nationality are reported. Vignettes 2, 3, 5, and 9 resulted in significant three-way interactions between nationality, gender, and vignettes. These significant effects suggest that Turkish women, relative to U.S. women, are more sensitive to ethical dilemmas on Vignettes 2 and 5. Turkish males are more sensitive than are U.S. males on Vignette 3. These are the same vignettes in which there were significant differences between the two countries, and the differences were in the same direction. This suggests that Turkish participants' greater emphasis on responsibilities to clients arose because of significant differences between women on Vignettes 2, 5, and between men for Vignette 3. On Vignette 9, which reported greater ethical sensitivity among U.S. respondents, relative to the Turkish participants, the difference appears to arise from the difference between U.S. women and Turkish women. Hence, the effect depends on both gender and nationality.

\section{Responsibilities to society}

The multivariate tests of ethical sensitivity to dilemmas involving duties to society found significant differences for Vignette $(F=24.370$, $p<0.0001)$. None of the two- or three-way interactions are statistically significant. This result indicates that ethical sensitivity to third party and social issues varied by vignette within the society category. One explanation for not finding between subject effects is the concept of moral intensity, which is influenced by the magnitude, uncertainty, temporal, physical and psychological proximity of ethical dilemmas (Jones, 1991). Additionally, these vignettes involved issues in which the actors were not acting as principals or agents for the parties affected (i.e., the actions involved the general public or third parties). The mean responses to these vignettes were lower than the results to vignettes involving duties to agents or principals. The ethical link between individuals and society or third parties appears to be weak. When responsibilities to society are involved, ethical values do not appear to exert as much influence on the judgments of business executives and professionals as they do in dilemmas involving responsibilities to one's peers (agents) or principals (those to whom one has an explicit duty of care or responsibility). The ethical sensitivity to third parties appears to be unaffected by either Turkish or U.S. nationality or by gender. In this category we were unable to reject the null forms of our third and fourth hypotheses.

\section{Limitations}

The limitations of this study are similar to those of other studies in business ethics. Namely, that the scenarios used to elicit responses from participants are complex and lend themselves to varied interpretations. Further, questions may always be raised with respect to the validity of subjects' responses to the scenarios as measures of ethical sensitivity.

In addition, the sample studied may not be representative of Turkish and U.S. business executives and managers. Over $70 \%$ of the subjects in both countries were between the ages of 21 and 30 years old. Unlike the population of business executives, all of the subjects in the study held college degrees, and $10 \%$ of the U.S. sample, compared to $23 \%$ of Turkish sample, had graduate degrees. In addition, the earnings of the subjects were not measured. There is a large difference in nominal terms between the average earnings of U.S. and Turkish executives and managers. However, the subjects in this study have similar occupations and positions within their organizations. Although not tested, based upon the researchers' observations, the relative purchasing power of the respondents in the two countries may be similar. Additional research may be warranted to determine if our findings apply to other age groups, income and education levels.

The economies and cultures in the two countries from which the subjects were selected vary greatly. Turkey is a developing country with large differ- 
ences between the living conditions of the wealthy, middle class, and poor. High levels of inflation are present in Turkey, which contributes to a great deal of uncertainty regarding economic well being. In comparison, the U.S. economy is stable and dominant in international business. In the U.S., the middle-class is the largest group in terms of population. Perhaps more significant to this study of business ethics, the espoused values of the leaders in the U.S. are considered to be the values of the middle class from which the U.S. sample was selected. In Turkey, the professional and managerial class may not be perceived as the mainstream with respect to ethical values. Therefore the results of this study may not apply to the general population of businessmen and women in Turkey. Further, the gender differences found in this sample of similarly educated and employed men and women may not extend to men and women from different economic and social backgrounds.

Even though the Hofstede dimensions are widely utilized in cross-cultural research in accounting, marketing, human resource management, sociology and psychology (e.g., Blodgett et al., 2001; Chow et al., 1994; Chow et al., 1996; Chow et al., 1999; Fijneman et al., 1996; Frucot and Shearon, 1991; Harrison, 1992, 1993; Harrison et al., 1994; Jackson, 2001; Lau et al., 1995; Lincoln et al., 1986; Mc Sweeney, 2002; Nakata and Sivakumar, 1996; O'Connor, 1995; Vance et al., 1992), some researchers question the applicability of these dimensions to different cultures. For detailed discussions, see Harrison and McKinnon (1999) and Baskerville (2003). The national differences observed in Hofstede's $(1980,1991)$ studies were based on the responses of professionals working for a multinational company. Participants in the current study were business executives and professionals sharing the same middle and upper class socioeconomic characteristics that were represented in the Hofstede studies. Our view is that the cultural dimensions theorized by Hofstede to reflect differences between employees in Turkey and the U.S., among other countries, may contribute to understanding the differences observed in this study between managers and executives from the two countries. Further research may either confirm or reject these findings.

\section{Conclusions}

The current study examined the ethical sensitivity of managers from two very different countries, the U.S. and Turkey. Ethical sensitivity was investigated through the participants' responses to 16 vignettes covering three main issues: ethical duties to principals, agents, and society. The results obtained in the study show that, as hypothesized, there are significant differences among the three categories of vignettes. Overall, ethical sensitivity to issues involving agents is highest, ethical sensitivity to principals is in second place, and ethical sensitivity to society or third parties is lowest. The explanations for the differences are supported by Jones' (1991) issue-contingent model. The finding that ethical sensitivity varied across duties owed to principals, agents and society is consistent with the law of agency and Kohlberg's (1976) work on stages of moral development. We find that agents are more sensitive to "agent" or employee-related issues, suggesting that they identify with the actions depicted in the vignettes. Thus, our findings agree with earlier research indicating that people are more sensitive to potential wrongs to themselves than they are to potential wrongs to others with whom they have weaker bonds.

Analysis of between-subjects effects showed that gender is a significant factor in the agent-related cases. Women in this study displayed higher ethical sensitivity than did men in the agent-related cases. This may well be viewed as demonstrating that women's moral decision-making process focuses on ethics of care, again confirming earlier research. Another aspect of the greater sensitivity of women than men to the agency dilemmas may be that men are unable to identify with, or recognize, potential harm to women because they are less likely to have been the recipients of gender discrimination.

When responsibilities to principals are tested, failure to reject the null in comparisons between men and women may be explained by structural theory. According to this theory, differences between men and women in social roles are dominated by the rewards/costs associated with occupational roles; thus, the two genders are expected to react similarly in the same occupational environments (Betz et al., 1989). The structural approach 
suggests that men and women become similar when they go through the same training. In the same professional settings, they respond similarly. This approach seems to provide an explanation for the lack of differences in the principal context.

In contrast to the results for gender on principalrelated issues, we were able to reject the null hypotheses stating that nationality has no affect on ethical sensitivity to principals. Previous research on human resource management and leadership revealed significant differences in the management styles of Turkish and American managers, especially in their attitudes toward power distance. Turkish managers, compared to U.S. managers, place less emphasis on individualism and the importance of freedom of choice. We find reflections of these traits in our analysis, signifying nationality effects in the issues related to principals. Differences in power distance and individualism/collectivism and the different ethical decision making approaches attributed to the countries, i.e., "ethics of care" emphasized in Turkey and "ethics of justice" emphasized in U.S., exist in concert to create the between subjects ethical sensitivity to principals differences observed in the participants.

The findings of the current research extend our understanding of how individuals are affected by the moral intensity of the issues, by nationality and gender characteristics. Our findings imply that resolution of an ethical dilemma is dependent upon the issue involved to a greater degree than it is on the gender or the nationality of the person faced with an ethical dilemma. Previous research demonstrated the relation between firm ethicality and performance on one hand, and the association of employing host country ethical rules to achieve economic gain on the other hand (Asgary and Mischow, 2002). The results of the current study suggest some areas where companies may find the greatest ethical rule discrepancies in different nations. Knowledge of such cross-national variations may aid managers in their efforts to attain a more harmonious organizational atmosphere that utilizes the benefits of diversity.

Though unfortunate from the perspective of addressing ethical issues, it should be noted that ethical sensitivity to issues involving potential harm to society through environmental degradation, product safety violations, and misleading financial statements elicited the lowest measures of ethical sensitivity. Moreover, our findings revealed no statistically significant differences in ethical sensitivity between women and men or between the U.S. and Turkish managers and executives regarding ethical duties to society or third parties. These findings reflect the negative consequences of an absence of perceived psychological proximity on ethical judgments. If the interests of society are to be protected when ethical dilemmas arise in business organizations, additional research may be needed. We have not learned how to raise the ethical sensitivity of decision-makers to the importance of protecting society's interests.

\section{Acknowledgements}

Previous versions of this paper were presented at the 38th Annual Western Region American Accounting Association Meeting, Colorado, April 2003 and the Eighth Annual Symposium on Ethics Research in Accounting, American Accounting Association on Professionalism and Ethics Committee, Honolulu, Hawaii, August 2003. The authors sincerely thank the session participants and the anonymous reviewers for the Journal and Business Ethics for their helpful comments.

\section{APPENDIX A}

Illustrative vignette

[Agent]

Sybil started to work as the marketing manager in a new firm about a month ago. The new firm is the competitor of her old firm in which she worked for 11 years. One day, the president of the new firm asks her to prepare a report that compares the distribution channels of the two firms. Sybil says she cannot prepare such a report because it would contain confidential information about her previous firm. However, the president argues that their firm is ready to provide any information requested, and thus, he expects the other firms should do the same. Moreover, he stresses that her loyalty is to the new 
firm. Sybil prepares the report and gives it to the president.

$*$ The behavior depicted in the vignette is:

\section{DEFINITELY \\ ETHICAL}

12

\section{DEFINITELY \\ UNETHICAL}

\section{References}

Ameen, E. C., D. M. Guffey and J. J. McMillan: 1996, 'Gender Differences in Determining the Ethical Sensitivity of Future Accounting Professionals', Journal of Business Ethics 15, 591-597.

Arlow, P.: 1991, 'Personal Characteristics on College Students' Evaluations of Business Ethics and Corporate Social Responsibility', Journal of Business Ethics 10, 63-69.

Asgary, N. and M. C. Mitschow: 2002, 'Toward a Model for International Business Ethics', Journal of Business Ethics 36, 239-246.

Aycan, Z., R. N. Kanungo and J. B. P. Sinha: 1999, 'Organizational Culture and Human Resource Management Practices: The Model of Culture-Fit', Journal of Cross-Cultural Psychology 30(4), 501-526.

Aycan, Z., R. N. Kanungo, M. Mendonca, K. Yu, J. Deller, G. Stahl and A. Kurshid: 2000, 'Impact of Culture on Human Resource Management Practices: A 10 Country Comparison', Applied Psychology: An International Review 49(1), 192-221.

Barnett, J. H. and M. J. Karson: 1989, 'Managers, Values, and Executive Decisions: An Exploration of the Role of Gender, Career Stage, Organizational Level, Function and the Importance of Ethics, Relationships, and Results in Managerial Decision Making', Journal of Business Ethics 8, 747-771.

Baskerville, R. F.: 2003, 'Hofstede Never Studied Culture', Accounting, Organizations and Society 28, 1-14.

Beck, B. F. and L. F. Moore: 1985, 'Linking the host culture to organizational variables', in P. J. Frost (ed.), Organizational Culture (Sage Publications, Beverly Hills, CA), pp. 335-354.

Beltramini, R. F., R. A. Peterson and G. Kozmetsky: 1984, 'Concerns of College Students Regarding Business Ethics', Journal of Business Ethics 3, 195200.

Betz, M., L. O'Connell and J. M. Shepard: 1989, 'Gender Differences in Proclivity for Unethical Behavior', Journal of Business Ethics 8, 321-324.

Blanchard, K.: 1998, 'The New Bottom Line', Entre preneur, February, 127-131.
Blodgett, J. G., L. Lu, G. M. Rose and S. J. Vitell: 2001, 'Ethical Sensitivity to Stakeholder Interests: A CrossCultural Comparison', Journal of the Academy of Marketing Science 29(2), 190-202.

Boatright, J. R.: 1992, 'Conflict of interest: an agency analysis', in N. E. Bowie and R. E. Freeman (eds.), Ethics and Agency Theory (Oxford University Press, New York), pp. 187-203.

Coate, C. J. and K. J. Frey: 2000, 'Some Evidence on the Ethical Disposition of Accounting Students: Context and Gender Implications', Teaching Business Ethics 4, 379-404.

Chow, C. W., Y. Kato and M. D. Shields: 1994, 'National Culture and the Preference for Management Controls: An Exploratory Study of the Firm-Labor Market Interface', Accounting, Organizations and Society 19, 381-400.

Chow, C. W., Y. Kato and K. A. Merchant: 1996, 'The Use of Organizational Controls and Their Effects on Data Manipulation and Management Myopia: Japan versus U.S. Comparison', Accounting, Organizations and Society 21, 175-192.

Chow, C. W., G. L. Harrison, J. L. McKinnon and A. Wu: 1999, 'Cultural Influences on Informal Information Sharing in Chinese and Anglo-American organizations: An exploratory Study', Accounting, Organizations and Society 24, 561-582.

Cohen, J., L. W. Pant and D. J. Sharp: 1998, 'The Effect of Gender and Academic Discipline Diversity on the Ethical Evaluations, Ethical Intentions, and Ethical Orientation of Potential Public Accounting Recruits', Accounting Horizons 12(3), 250-270.

Cole, B. C. and D. L. Smith: 1996, 'Perceptions of Business Ethics: Students versus Business People', Journal of Business Ethics 15, 889-896.

Collins, D.: 2000, 'The Quest to Improve the Human Condition: The First 1500 Articles Published in Journal of Business Ethics', Journal of Business Ethics 26, $1-73$.

Crow, S., L. Fok, S. Hartman and D. Payne: 1991, 'Gender and Values: What is the Impact on DecisionMaking?', Sex Roles 25(3/4), 255-268.

Cyert, R. M. and J. G. March: 1963, A Behavioral Theory of the Firm (Prentice-Hall, Inc., Englewood Cliffs, NJ).

Davis, J. R. and R. E. Welton: 1991, 'Professional Ethics: Business Students' Perceptions', Journal of Business Ethics 10, 451-463.

Dawson, L. M.: 1995, 'Women and Men, Morality and Ethics', Business Horizons 38(4), 61-69.

Derry, R.: 1987, 'Moral Reasoning in Work-Related Conflicts', in W. C. Frederick (ed.), Research in Corporate Social Performance and Policy, Vol. 9 (JAI Press, Greenwich, CT). 
Derry, R.: 1989, 'An Empirical Study of Moral Reasoning Among Managers', Journal of Business Ethics 8, 855-862.

Dienhart, J.: 1995, 'Rationality, Ethical Codes and an Egalitarian Justification for Ethical Expertise', Business Ethics Quarterly 5, 419-450.

Dobbins, G. H. and S. J. Platz: 1986, 'Sex Differences in Leadership: How Real are They?', Academy of Management Review 11(1), 118-127.

Douglas, P. C. and B. N. Schwartz: 1999, 'Values as the foundation for moral judgments: theory and evidence in an accounting context', in L. A. Ponemon (ed.), Research on Accounting Ethics, vol. 5 (JAI Press, Greenwich, CT), pp. 3-20.

Dubinsky, A. J. and M. Levy: 1985, 'Ethics in Retailing: Perceptions of Retail Salespeople', Journal of Academy of Marketing Science 13(1), 1-16.

Fijneman, Y. A., M. E. Willemsen,Y. H. Poortinga, with F. G. Erelcin, J. Georgas, C. H. Hui, , K. Leung and R. S. Malpass: 1996, 'Individualism - Collectivism: An Empirical Study of a Conceptual Issue', Journal of Cross-Cultural Psychology 27(4), 381-402.

Fikret-Pasa, S., H. Kabasakal and M. Bodur: 2001, 'Society, Organizations, and Leadership in Turkey', Applied Psychology: An International Review 50(4), 559-589.

French, W. and A. Weis: 2000, 'An Ethics of Care or an Ethics of Justice', Journal of Business Ethics 27, 125-136.

Frucot, V. and W. T. Shearon: 1991, 'Budgetary Participation, Locus of Control, and Mexican Managerial Performance and Job Satisfaction', The Accounting Review 66, 80-99.

Galbraith, S. and H. B. Stephenson: 1993, 'Decision Rules Used by Male and Female Business Students in Making Ethical Value Judgments: Another Look', Journal of Business Ethics 12, 227-233.

Gibson, K.: 1995, 'Fictitious Persons and Real Responsibilities', Journal of Business Ethics 14, 761-767.

Gibson, K.: 1999, 'Role Morality and Individual Moral Responsibility in Accounting', Current Topics in Management 4, 81-97.

Gibson, K.: 2000, 'The Moral Basis of Stakeholder Theory', Journal of Business Ethics, 26, 245-257.

Gilligan, C.: 1982, In a Different Voice (Harvard University Press, Cambridge, MA).

Goodpaster, K.: 1991, 'Business Ethics and Stakeholder Analysis,' Business Ethics Quarterly 1(1), 53-74.

Harris, J. R.: 1989, 'Ethical Values and Decision Processes of Male and Female Business Students', Journal of Business Ethics 8, 234-238.

Harris, J. R., and C. D. Sutton: 1995, 'Unraveling the Ethical Decision-Making Process: Clues From an
Empirical Study Comparing Fortune 1000 Executives and MBA Students', Journal of Business Ethics 14, 805-817.

Harrison, G. L.: 1992, 'The Cross-Cultural Generalizability of the Relation Between Participation, Budget Emphasis and Job Related Attitudes', Accounting, Organizations and Society 17, 1-15.

Harrison, G. L.: 1993, 'Reliance on Accounting Performance Measures in Superior Evaluative Style - the Influence of National Culture and Personality', Accounting, Organizations and Society 18, 319-339.

Harrison, G. L. and J. L. McKinnon: 1999, 'Cross-Cultural Research in Management Control Systems Design: A Review of the Current State', Accounting, Organizations and Society 24, 483-506.

Harrison, G. L., J. L. Mc Kinnon, S. Panchapakesan and M. Leung: 1994, 'The Influence of Culture on Organizational Design and Planning and Control in Australia and the United States Compared with Singapore and Hong Kong', Journal of International Financial Management and Accounting 5, 242-261.

Hegarty, W. H. and H. P. Sims Jr.: 1978, 'Some Determinants of Unethical Decision Behavior: An Experiment', Journal of Applied Psychology 63, 451-457.

Hegarty, W. H. and H. P. Sims Jr.: 1979, 'Organizational Philosophy, Policies, and Objectives Related to Unethical Decision Behavior: A Laboratory Experiment', Journal of Applied Psychology 64, 331-338.

Hofstede, G.: 1980, Culture's Consequences : International Dierences in Work-Related Values (Sage Publications, Beverly Hills, CA).

Hofstede, G.: 1991, Cultures and Organizations: The software of the mind (McGraw Hill Co., London, $\mathrm{UK})$.

Hunt, S. D. and S. Vitell: 1986, 'A General Theory of Marketing Ethics', Journal of Macromarketing 6(1), 5-16.

Jackson, T.: 2001, 'Cultural Values and Management Ethics: A 10-Nation Study', Human Relations 54(10), 1267-1302.

Jones, T. M.: 1991, 'Ethical Decision Making by Individuals in Organizations: An Issue Contingent Model', Academy of Management Review 16(2), 366-395.

Jones, T. M. and F. H. Gautschi II: 1988, 'Will the Ethics of Business Change? A Survey of Future Executives', Journal of Business Ethics 7, 231-248.

Joyner, B. E. and D. Payne: 2002, 'Evolution and Implementation: A study of values, business ethics and corporate social responsibility', Journal of Business Ethics 41, 297-311.

Kasaba, R. and S. Bozdogan: 2000, 'Turkey at a Crossroad', Journal of International Affairs 54(1), 1-20. 
Kidwell, J., R. Stevens and A. Bechke: 1987, 'Differences in Ethical Perceptions Between Male and Female Managers: Myth or Reality?', Journal of Business Ethics 6, 451-457.

Kohlberg, L.: 1976, 'Moral Stages and Moralization: The Cognitive-Development Approach', in T. Lickona (ed.), Moral Development and Behavior: Theory, Research, and Social Issues (Holt, Rinehart and Winston, New York), pp. 31-53.

Larkin, J. M.: 2000, 'The Ability of Internal Auditors to Identify Ethical Dilemmas', Journal of Business Ethics 23(4), 401-409.

Lau, C. M., L. C. Low and I. R. C. Eggleton: 1995, 'The Impact of Reliance on Accounting Performance Measures on Job Related Tension and Managerial Performance: Additional Evidence', Accounting, Organizations and Society 20, 359-381.

Lessnoff, M.: 1986, Social Contract (Humanities Press International, Inc., Atlantic Highlands, NJ).

Lincoln, J. R., M. Hamada, and K. McBride: 1986, 'Organizational Structures in Japanese and US Manufacturing', Administrative Science Quarterly 31, 338-364.

Lyons, N.: 1988, Two Perspectives: 'On Self Relationships and Morality', in C. Gilligan, J. V. Ward, J. McLean Taylor and B. Bardige (eds.), Mapping the Moral Domain: A Contribution of Women's Thinking to Psychology and Education (Harvard University, Graduate School of Education, Cambridge, MA).

MacIntyre, A.: 1984, After Virtue: A Study in Moral Theory, 2nd Edition (University of Notre Dame Press, Notre Dame, IN).

Mc Cabe, D., J., Dukerich and J. Dutton: 1991, 'Context, Values and Moral Dilemmas: Comparing the Choices of Business and Law School Students', Journal of Business Ethics 10, 951-960.

Mc Sweeney, B.: 2002, 'Hofstede's Model of National Cultural Differences and their Consequences: A Triumph of Faith - a Failure Analysis', Human Relations 55(1), 89-118.

Mc Nichols, C. W. and T. W. Zimmerer: 1985,'Situational Ethics: An Empirical Study of Differentiators of Student Attitudes', Journal of Business Ethics 4, 175-180.

Miesing, P. and J. F. Preble: 1985, 'A Comparison of Five Business Philosophies', Journal of Business Ethics 4, 465-476.

Nakata, C. and K. Sivakumar: 1996, 'National Culture and New Product Development: An Integrative Review', Journal of Marketing 60, 61-72.

Newman, K. L. and S. D. Nollen: 1996, 'Culture and Congruence: The Fit Between Management Practices and National Culture', Journal of International Business Studies 26(4), 753-779.

O'Connor, N. G.: 1995, 'The Influence of Organizational Culture on the Usefulness of Budget Participation by Singaporean-Chinese Managers', Accounting, Organizations and Society 20, 383-403.

Peterson, R., R. Beltramini and G. Kozmetsky: 1991, 'Concerns of College Students Regarding Business Ethics: A Replication', Journal of Business Ethics 10, 733-738.

Piaget, J.: 1965, The Moral Judgment of the Child (trans. M. Grabain) (The Free Press, New York, 1965), p. 398, as cited in Velasquez, 1982.

Ponemon, L. A.: 1992, 'Ethical Reasoning and SelectionSocialization Accounting', Accounting, Organizations and Society 17(3,4), 239-258.

Poorsolton, K., S. G. Amin and A. Tootoonchi: 1991, 'Business Ethics: Views of Future Leaders', SAM Advanced Management Journal 56, 4-9.

Quinn, D. and T. Jones: 1995, 'An Agent Morality View of Business Policy', Academy of Management Review 20(1), 22-42.

Radtke, R. R.: 2000, “The Effects of Gender and Setting on Accountants' Ethically Sensitive Decisions', Journal of Business Ethics 24(4), 299-312.

Reiter, S. A.: 1996, 'The Kohlberg-Gilligan Controversy: Lessons for Accounting Ethics Education', Critical Perspectives on Accounting 7(1), 33-54.

Rest, J. R.: 1986, Moral Development: Advances in Research and Theory (Praeger, NY).

Rettinger, D. A. and R. Hastie.: 2001, 'Content Effects on Decision Making', Organizational Behavior and Human Decision Processes 85, 336-359.

Robertson,C. J., W. F., Crittenden, M. K., Brady and J. J. Hoffman: 2002, 'Situational Ethics Across Borders: A MulticulturalExamination', Journal of Business Ethics 38, 327-338.

Ronen, S: 1986, Comparative and Multinational Management (John Wiley \& Sons, NY).

Ruegger, D. and E. W. King: 1992, 'A Study of the Effect of Age and Gender upon Student Business Ethics', Journal of Business Ethics 11, 179-186.

Schein, E. H.: 1965, Organizational Psychology (PrenticeHall, Inc., Englewood Cliffs, NJ).

Schwartz, M.: 2002, 'A Code of Ethics for Corporate Code of Ethics', Journal of Business Ethics 41, 27-43.

Schwartz, S. H.: 1994, 'Cultural Dimension of Values: Towards an Understanding of National Differences', in U. Kim, H. C. Triandis, C. Kagitcibasi, S. C. Choi and G. Yoon (eds.), Individualism and Collectivism: Theoretical and Methodological Issues (Sage Publications, Thousands-Oaks), pp. 85-119. 
Simga-Mugan, C. and D. Onkal-Atay: 2003, 'Contextual Effects on Ethical Sensitivity and Penalty Judgments: The Turkish Case', Teaching Business Ethics, 7(4), 341-363.

Sinha, J. N. P. and J. Verma: 1987, 'Structure of Collectivism', in C. Kagitcibasi (ed.), Growth and progress in Cross-Cultural Psychology ( Swets and Zeitlinger, Lisse, The Netherlands).

Stodder, G. S.: 1998, 'Goodwill Hunting', Entrepreneur (July), 118-121.

Tabachnick, B. G. and L. S. Fidell: 1996, 'Using Multivariate Statistics, 3rd Edition (Harper Collins, NY).

Thorne, L.: 1998, 'The Role of Virtue in Auditors' Ethical Decision Making: An Integration of Cognitive-Developmental and Virtue-Ethics Perspectives', in L. A. Ponemon (ed.), Research on Accounting Ethics, Vol. 4 (JAI Press Inc., Greenwich, CT), pp. 291-308.

Trevino, L.: 1992, 'Moral Reasoning and Business Ethics: Implications for Research, Education, and Management', Journal of Business Ethics 11, 445-459.

Trompenaars, F. and C. Hampden-Turner: 1998, Riding the Waves of Culture: Understanding Cultural Diversity in Global Business, 2nd Edition (McGrawHill Co., NY).

Tronto, J. C.: 1993, Moral Boundaries (Routledge, New York).

Tsalikis, J. and M. Ortiz-Buonafina: 1990, 'Ethical Beliefs' Differences of Males and Females', Journal of Business Ethics 9, 509-517.

Tsalikis, J., B. Seaton and P. Tomaras: 2002, 'A New Perspective on Cross-Cultural Ethical Evaluations: The Use of Conjoint Analysis', Journal of Business Ethics 35(4), 281-292.

Vance, C. M., S. R. McClaine, D. M. Boje and D. Stage: 1992, 'An Examination of the Transferability of Traditional Performance Appraisal Principles Across Cultural Boundaries', Management International Review 32, 313-326.

Velasquez, M. G.: 1982, Business Ethics: Concepts and Cases (Prentice Hall, Inc., Englewood Cliffs, NJ).
Velasquez, M. G. and C. Rostantowski: 1985, Ethics Theory and Practice (Prentice Hall, Inc., Englewood Cliffs, NJ).

Verma, J.: 1992, 'Allocentrism and Relational Orientation', in S. Iwawaki, Y. Kashima and K. Leung (eds.), Innovation in Cross-Cultural Psychology (Swets and Zeitlinger, Amsterdam, The Netherlands).

Weber, J.: 1990, 'Managers' Moral Reasoning: Assessing their Responses to three Moral Dilemmas', Human Relations 43(7), 687-702.

Can Simga-Mugan Department of Business Administration, Middle East Technical University, Ankara, Turkey E-mail:mugan@metu.edu.tr

Bonita A. Daly School of Business, University of Southern Maine, Portland,

P.O. Box 9300,

ME 04104, USA

E-mail:bdaly@maine.edu

Dilek Onkal Faculty of Business Administration, Bilkent University, Ankara, Turkey

Lerzan Kavut Faculty of Business Administration, Istanbul University, Istanbul, Turkey 